\title{
Evaluating Market Benefits of Transportation Tunnels-The Carmel Tunnels as a Case Study
}

\author{
Ofira Ayalon ${ }^{1,2^{*}}$, Lior Shmueli ${ }^{3}$, Shiri Freund Koren ${ }^{2}$, Maayan Zion Zerbib ${ }^{2}$ \\ ${ }^{1}$ Department of Natural Resources \& Environmental Management, Faculty of Management, University of Haifa, Haifa, Israel \\ ${ }^{2}$ Samuel Neaman Institute, Technion, Haifa, Israel \\ ${ }^{3}$ EcoFinance-Consulting \& Responsible Investments, Ramat Gan, Israel \\ Email: *Ofira@sni.technion.ac.il
}

How to cite this paper: Ayalon, O., Shmueli, L., Koren, S.F. and Zerbib, M.Z. (2016) Evaluating Market Benefits of Transportation Tunnels-The Carmel Tunnels as a Case Study. Journal of Environmental Protection, 7, 1259-1272.

http://dx.doi.org/10.4236/jep.2016.710111

Received: June 19, 2016

Accepted: September 10, 2016

Published: September 13, 2016

Copyright $\odot 2016$ by authors and Scientific Research Publishing Inc. This work is licensed under the Creative Commons Attribution International License (CC BY 4.0).

http://creativecommons.org/licenses/by/4.0/

\begin{abstract}
Since opening in 2010, The Carmel Tunnels have redirected some of the traffic from within the City of Haifa in Israel. This paper studies the direct and indirect financial and environmental benefits of the Carmel Tunnels compared to alternative routes. Direct benefits for drivers include financial savings thanks to savings on time and gas. Indirect benefits for drivers and for the public include reduced air pollution, greenhouse gas emissions and noise. Results show significant positive benefits from using the Carmel Tunnels compared to various alternative routes (i.e., reference scenarios). During peak hours ( 8 am and $4 \mathrm{pm}$ ), when there is heavy traffic on the alternative routes, the total benefits increase by about $25 \%-47 \%$. Using tunnels for transportation allows, among other benefits, efficient use of underground land, redirecting traffic congestion from town centers, decreasing landscape damage due to major roads passing through open spaces, and reducing air pollution in residential areas.
\end{abstract}

\section{Keywords}

Road Tunnel, Traffic Air Pollution, Traffic Noise, Alternative Routes

\section{Introduction}

The demand for land in cities is increasing constantly. Higher prices and costs of above ground open possible uses underground-mainly municipal and transportation infrastructure.

Underground infrastructure can provide location of activities or infrastructures that are difficult, impossible, environmentally undesirable or less profitable to install above ground. Underground provides mechanical, thermal and acoustical protection, as well 
as protecting the surface environment from the risks and/or disturbances, such as air pollution and providing aesthetically acceptable landscape [1] [2].

\subsection{Main Motives for Underground Building in Developed Countries}

Population density in large cities-Accelerated urbanization processes around the world has led to increased urban populations, resulting in a high demand for residential and service areas. Intensive use of the land has become necessary due to population density and high prices of land. Therefore, transferring various uses underground, especially municipal and transportation infrastructure and facilities, is an obvious solution to this problem.

Insulation and Isolation-Underground facilities can provide isolation from noise and environmental conditions such as air pollution [3], and can provide natural insulation for underground buildings and systems, thereby decreasing the need for heating or cooling, and resulting in energy savings. The underground use and tunnels are specifically important with regards to climate changes. In the Climate Change Adaptation Report for Israel [4] the team that dealt with geostrategic aspects determined that tunnels are a possible solution for climate change adaptation, but stated that no in-depth research has yet been conducted on the topic of tunnels in Israel as a solution for dealing with the general warming and dryness (e.g., research on various uses, drilling and maintenance costs, and safety). They further stated that the option of "going underground" as a comprehensive strategy that could solve state requirements should also be researched, such as excessive land use and security issues. For example, [3] claim that underground facilities could provide protection for civilians and for strategic facilities against attacks such as bombings.

\subsection{Tunnels as an Alternative to Conventional Roads}

Higher levels of motorization are driven by population growth and higher standards of living. The number of vehicles around the world increases from year to year [5], with most cars being fueled by fossil fuel which increases air pollution and in turn affects people's health. Over the years, tunnels and additional engineering methods have been developed for improving traffic flow and decreasing traffic congestion, travel times, fuel consumption and air pollution, in order to address this issue.

With regards to travel times to and from work, it should be noted that this affects both employees and their families. It was found that in Italy [6], an 1\% increase in the husband's travel time to work decreases the chance of his wife entering the employment market by $2 \%$ above the average rate (due to the need for one of the parents to look after the children). This same $1 \%$ increase in travel time also increases the number of hours that the husband is out of the house by 0.2 hours. Therefore, a solution that reduces this type of travel time would be greatly beneficial.

\subsection{Pollution from Transportation}

There is growing evidence as to a connection between vehicle pollutants and severe 
health problems, such as lung cancer, respiratory illnesses and cardio-pulmonary diseases [7]. Moreover, according to the World Health Organization (WHO), emissions from car exhausts are responsible for more deaths than road accidents worldwide [8]. In 2012, [9] found that the overall annual costs for the Israeli market as a result of transportation-related pollution was NIS 8.4B.

Transportation-related air pollution is caused by emission of air pollutants such as particulate matter $(\mathrm{PM})$, nitrogen oxides $\left(\mathrm{NO}_{\mathrm{x}}\right)$ and volatile organic compounds (VOC). Such air pollution leads to increased health costs and damage to buildings and materials. The ecosystem is also negatively affected, with crop losses and damages caused to the biosphere, soil and water. However, health costs caused by these pollutants are by far the most important cost category (e.g., [10]).

As car exhaust emissions occur relatively close to the ground, they have a greater negative effect than stationary pollution caused by industry or electrical production that is emitted tens and even hundreds of meters above the ground-resulting in much higher financial costs, especially due to severe negative health effects.

A strong relationship was found between a range of respiratory diseases among children in Nigeria and their exposure to traffic pollution, with the strongest link being found in areas with extreme truck traffic [11]. A study conducted by [12] also supports the claim that the risk of developing lung cancer is associated with air pollution caused by traffic near residential areas.

It is important to that note that research does show that air pollution can also accumulate inside underground traffic tunnels [13] [14]-a suggested alternative for reducing air pollution-yet the underlying assumption is that tunnels can reduce municipal air pollution, ensuring their value is greater than their risk. In a study conducted by [15], the researchers found positive changes in levels and distribution of over-ground air pollution following the opening of underground traffic tunnels. However, although air filter systems and treatment do exist, most tunnels only have aeration systems and air quality assurance systems that filter the pollution out of the tunnel, as do the Carmel Tunnels in Haifa, Israel, that were studied in this paper (according to personal communications with Carmelton who operates the Carmel Tunnels).

It was found [16] that annual monitoring data of $\mathrm{NO}_{\mathrm{x}}$ in traffic stations in Haifa did not show a significant decrease in pollution concentrations following the opening of the Carmel Tunnels (mainly due to an annual increase of about 3\% - 4\% in the number of new vehicles on the roads in Israel and in the Haifa area, and to regulatory changes that reflect environmental standards and vehicle pollutant standards in Israel-especially the enforcement of the "Euro 5" standard in Israel). However, when the data was analyzed based on short-term monitoring (hourly or daily), a significant decrease could be seen in levels of $\mathrm{NO}_{2}$ concentrations in the "Ahuza" Traffic Station (located in Horev, see Map 1), following the opening of the Carmel Tunnels.

\subsection{Noise from Traffic}

The noise generated by driving vehicles affects a large number of people and during 


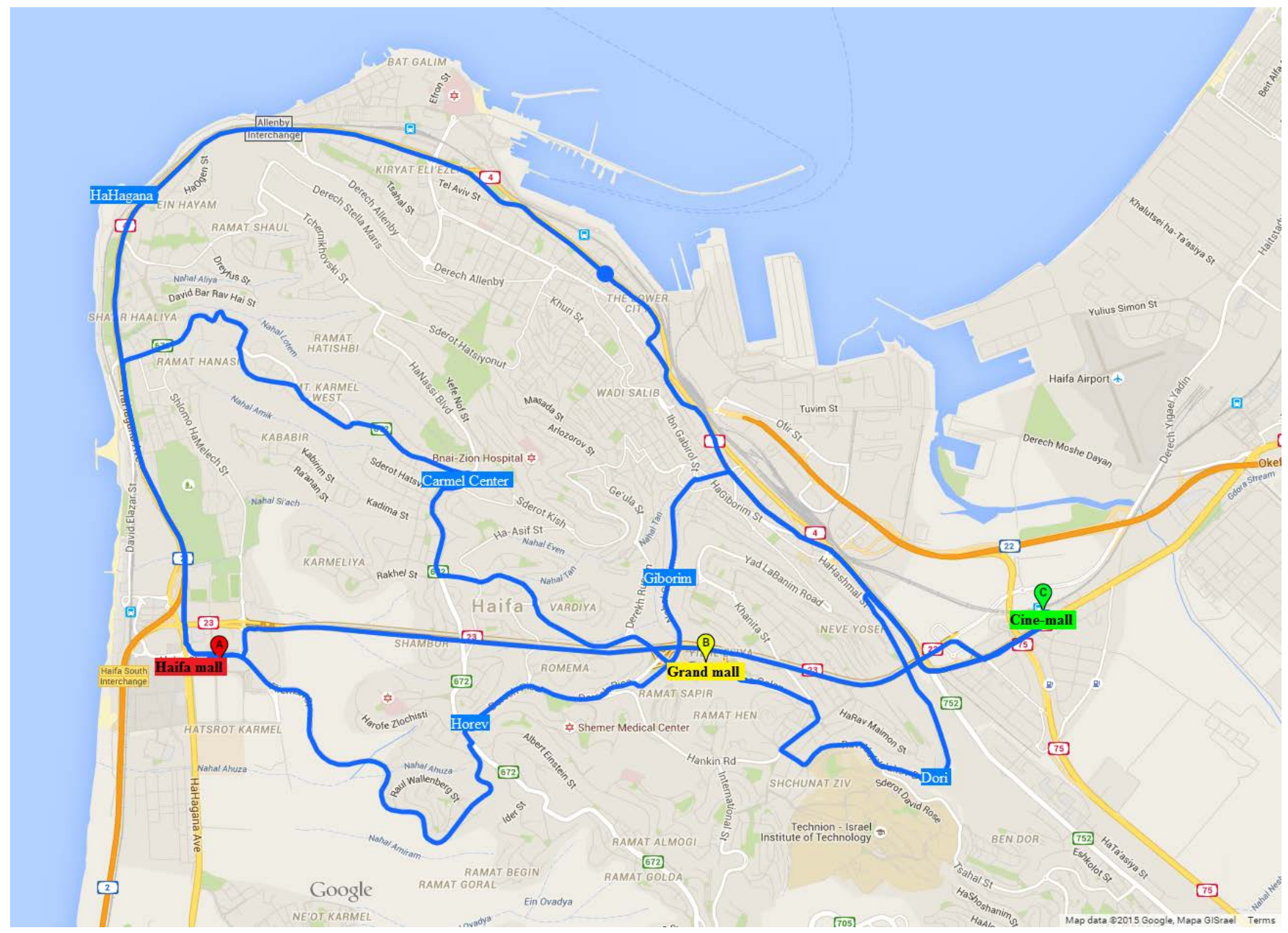

Map 1. Routes analyzed: A-B-C represent the Carmel Tunnels. Routes via Horev and Carmel Center represent alternative to A-B section, Hagiborim and Dori represent alternatives to B-C section, HaHagana represents another alternative to the above to A-C sections.

most hours of the day-especially populations who are situated near main roads and junctions. In addition to affecting their quality of life, this noise also leads to depreciation in value of their homes and properties.

Levels of noise caused by transportation are mainly influenced by the following factors [17]: Volume of traffic, types of vehicles (heavy vehicles such as buses and trucks generate more noise than motorbikes, for example), speed of driving, type of flow, age of the vehicle and level of maintenance, including tires maintenance.

By building underground, the ground itself provides isolation from noise. Therefore, redirecting traffic through underground tunnels decreases both traffic congestion and noise on main roads or in nearby residential areas.

\section{The Research Zone}

Haifa City is a continuously growing transportation, industry and culture center, with its port making it one of Israel's major commercial zones. Each year, the number of cars travelling in and through Haifa increases significantly. Opening the Carmel Tun- 
nels at the end of 2010, therefore, was aimed at decreasing traffic congestion, at the city's entrances and exits, at the city center, and on roads to industrial and technological centers within the city. The Carmel Tunnels are a toll road, with entrances and exits at Haifa Mall, Grand Mall and Cine Mall (as presented in Map 1). The driver can choose to drive along one or two sections of the tunnels. Data collected from main roads in Haifa before and after the opening of the Carmel Tunnels showed that following the opening of the tunnel, there was an average of about $20 \%$ less vehicles on those roads per day, with up to $40 \%$ decrease during the morning peak hour [16].

Map 1 presents the alternative roads and routes analyzed in this paper.

\section{Methods}

A dynamic financial Excel model was built to quantify direct financial benefits for users of the tunnels and indirect benefits for the general public derived from the Carmel Tunnels, compared to alternative transportation routes. Based on actual travel data for 2014, provided by Carmelton, this study calculated various benefits: time savings, fuel savings, air pollution savings, reduced greenhouse gas emissions, and reduced noise. The base scenario was driving via one or two sections of the tunnel, and for each section of the tunnel, two additional alternative traffic scenarios were chosen, i.e., nontunnel routes within the City of Haifa. The benefits were calculated as the difference between travel costs in each scenario compared to the relevant sections of the tunnels, and based on the actual volume of traffic in the tunnels during 2014 (from January to December).

For each scenario and section, data from $[18]^{1}$ was used regarding the length of the journey in terms of both kilometers and minutes/hours at various times of the day. In addition, as Haifa has a hilly topography, slopes were also calculated for each scenario in each section, based on data derived from [19].

Data derived from Google Earth and Waze enabled calculations of the following parameters:

- Distance (in km)

- Average travel time at regular hours and at peak hours (in minutes or hours)

- Average travel speed at regular hours and at peak hours (calculated by distance divided by time)

Travel speed was calculated as the average speed along the section, including time entering and exiting the tunnel, waiting at traffic lights, congestion, etc.

- Length of slopes in each relevant scenario (in $\mathrm{Km}$ )

- The average slope in each relevant scenario (in \%)

\subsection{Direct Benefits for Users}

\subsubsection{Time Savings}

Time savings were calculated as the difference (in hours) between the time the journey

${ }^{1}$ Waze is a Google's navigation application program for smartphones with GPS support and display screens which provides turn-by-turn information and user-submitted travel times and route details, downloading location-dependent information over mobile networks. 
took via one of the two alternatives (i.e., via a "reasonable route" or a longer route, as described on Map 1, compared to via the tunnel (A-B; B-C; A-C, or vice versa)-based on data retrieved from the Waze website.

As the length of times for each journey along the scenarios or tunnel sections differs depending on the time of day, calculations were based on average length of times and at peak hours ( 8 am, $4 \mathrm{pm}$ ).

The amount of time saved as a result of using the relevant section of the tunnel compared to the alternative scenarios was "translated" into financial benefits-based on the alternative cost of the time, which was estimated as the average hourly wage on the market (net values) of NIS 40 per hour ${ }^{2}$. In the case of a bus, which carries an average of 20 passengers including the driver, the benefit was calculated for each passenger and for the driver (NIS 800 per hour). In the case of a truck, the worth is higher and in Israel a wage of NIS 120 - 180 per work hour is the general average. In this case, NIS 150 was used.

\subsubsection{Fuel Savings}

Fuel savings were calculated as savings on fuel consumption for cars, buses and trucks (gasoline for cars, diesel for trucks and buses) that used the tunnels instead of an alternative route. Fuel consumption was calculated based on fuel emission factorsas specified in the Guidelines for Conducting an Environmental Survey of transportation-related air pollution prepared by [20]. These guidelines specify derivatives of fuel consumption based on greenhouse gas emissions, using emission factor of 2.32 and $2.67 \mathrm{Kg}$ of $\mathrm{CO}_{2}$ per liter of gasoline and diesel, respectively. Following the fuel consumption calculation for each scenario, the benefit was calculated as the difference between fuel consumption for driving via the tunnel and fuel consumption in the alternative scenarios.

Fuel savings were calculated in terms of liters of fuel saved, based on the August 2015 cost of NIS 6.5 (including 18\% VAT) per liter of gasoline for a car or per liter of diesel for a bus or truck.

The indirect benefits from using the tunnel were calculated based on the following methodology:

\subsection{Indirect Benefits}

\subsubsection{Savings on Air Pollution and Greenhouse Gas Emissions}

The level of emissions caused by vehicles depends on a number of factors, such as type and age of vehicle, type of fuel, speed of travel, slope of road, engine effort and vehicle maintenance.

In order to quantify greenhouse gases and other pollutant emissions caused by vehicles driving on any of the sections or scenarios, this study based its pollution emission factors on those published by [21].

These factors were determined based on certain models that included typical data for

${ }^{2}$ An hour was calculated based on the average salary in Israel, which at the time of writing this study was NIS 9200 (gross) per month, and with regards to the net salary, and 185 working hours per month. 
Israel and its vehicles. Emission factors are made up of the scope of pollutant emissions and greenhouse gases that are emitted while driving a vehicle (car, bus or truck) per unit of distance (gram to $\mathrm{km}$ of driving), dependent on the speed of driving (0 - 120 $\mathrm{km} / \mathrm{h})$ and the slope of the road $(+6 \%,+4 \%,+2 \%, 0 \%,-2 \%,-4 \%,-6 \%)$.

Savings on emissions were "translated" into financial benefits based on external cost values of air and greenhouse gas pollutants of 1.1.2015 [22], as presented in Table 1.

\subsubsection{Decreasing Noise}

From a methodological point of view, the working assumption is that driving through a tunnel does not cause traffic-related noise, as the noise is absorbed by the tunnel itself. Therefore, in order to evaluate the benefits of using the tunnel, the damage caused to Haifa residents as a result of using the alternative routes in the scenarios was also calculated. The cost of the damage was calculated based on external costs of noise as presented in the Economic Appraisal of Transportation Projects [23], prepared by the Israel Ministry of Transport and Road Safety with regards to city road sections.

Costs caused by noise in the city road sections of the reference scenarios were calculated based on the figures presented in Table 2.

Additional benefits that were not quantified in this study include the redirecting of traffic from the city center, reducing road congestion, reducing road and vehicle maintenance costs, developing and paving additional roads, using the underground area as a mass bomb shelter when needed, etc.

\section{Results and Discussion}

The calculated benefits include benefits generated by travelling via the tunnel (along one or two adjoining sections, at regular or peaks hours) and benefits for the Israeli market created thanks to the tunnel.

Table 1. External costs caused by air pollution from vehicles (for 1.1.2015).

\begin{tabular}{cc}
\hline Pollutant & NIS per ton emitted from vehicles \\
\hline $\mathrm{CO}$ & 1181 \\
$\mathrm{CO}_{2}$ & 119 \\
$\mathrm{HC}$ & 24,302 \\
$\mathrm{NO}_{\mathrm{x}}$ & 85,477 \\
$\mathrm{PM}$ (particulate matter) & 165,120 \\
Benzene & 24,302 \\
\hline
\end{tabular}

Table 2. Noise cost appraisal in municipal road sections by type of vehicle.

\begin{tabular}{ccc}
\hline Type of vehicle & $\begin{array}{c}\text { Cost of noise (NIS per km) } \\
\text { (present, 2015, value) }\end{array}$ & $\begin{array}{c}\text { Cost of noise (NIS per km) } \\
\text { (based on [23], 1999 prices) }\end{array}$ \\
\hline Truck & 0.122 & $\mathbf{0 . 0 9 3}$ \\
Bus & 0.079 & $\mathbf{0 . 0 6 0}$ \\
Car & 0.037 & $\mathbf{0 . 0 2 8}$ \\
\hline
\end{tabular}




\subsection{Average Benefits from Travelling via the Tunnels}

Table 3 presents the analysis of the benefit generated from driving along one or two sections of the tunnel (north-south; Haifa Mall-Grand Mall; or Grand Mall-Cine Mall) and at an average hour of the day.

In all cases, a positive benefit was found as a result of driving via the tunnel. The main benefits $(87 \%-96 \%)$ are direct benefits, including savings on time and fuel. The greatest benefit was for buses, as the large number of passengers led to a large time saving.

Further analysis (Figure 1) showed that in some cases the benefit of using the tunnels was higher than in other cases. For example, using the relevant tunnel section, instead of the alternative route from the Grand Mall to the Cine-Mall via Hagiborim Street, had a positive but low benefit (NIS 2.7, 35.5 and 8.5 for a car, bus and truck, respectively). In other examples, using the tunnel instead of an alternative regular route had a significantly high benefit, for example, driving from the Grand Mall to the Haifa Mall via the Carmel Center (NIS 24.2, 424 and 89.4 or a car, bus and truck, respectively). However, in this last case, the high benefit of driving via the tunnels was due to the length and slope of the alternative route, which in financial terms reached tens and even hundreds of NIS-making this alternative route irrelevant.

The benefit from driving a car is about $40 \%$ compared to buses, and about $50 \%$ compared to trucks. The main reasons for the differences between types of vehicles are fuel consumption, which is significantly higher for heavy vehicles than for cars, and air pollution, which is higher for diesel operated vehicles (buses and trucks) than for cars. The main direct benefits (time and fuel) for trucks, buses and cars comprise $87 \%, 96 \%$, $92 \%$, respectively of all total benefits. Due to the high hourly wage for trucks and buses, time savings comprise $62 \%$ - $87 \%$ of all benefits. Environmental benefits comprise $4 \%$ $13 \%$ of total costs. This is not surprising when evaluating trucks, as they operate on diesel (13\% of total costs), but for buses, the indirect benefits of reducing noise and air pollution only comprise $4 \%$ of the total costs, due to the high time costs of the 20 passengers.

Table 3. Benefits generated by travelling via the Carmel Tunnels at an average hour (in NIS).

\begin{tabular}{|c|c|c|c|c|c|c|}
\hline \multicolumn{7}{|c|}{ Average for one section } \\
\hline & Total & Fuel & Time & Noise & $\begin{array}{c}\text { Air } \\
\text { pollution }\end{array}$ & $\begin{array}{c}\text { Hourly } \\
\text { wage }\end{array}$ \\
\hline Truck & 22.10 & 5.39 & 13.75 & 0.85 & 2.11 & 150 \\
\hline Bus & 84.35 & 7.54 & 73.33 & 0.55 & 2.92 & 800 \\
\hline Car & 5.74 & 1.59 & 3.67 & 0.26 & 0.23 & 40 \\
\hline \multicolumn{7}{|c|}{ Average for two sections } \\
\hline & Total & Fuel & Time & Noise & $\begin{array}{c}\text { Air } \\
\text { pollution }\end{array}$ & $\begin{array}{c}\text { Hourly } \\
\text { wage }\end{array}$ \\
\hline Truck & 37.69 & 8.52 & 24.38 & 1.49 & 3.31 & 150 \\
\hline Bus & 146.64 & 11.32 & 130.00 & 0.96 & 4.36 & 800 \\
\hline Car & 9.80 & 2.49 & 6.50 & 0.45 & 0.36 & 40 \\
\hline
\end{tabular}




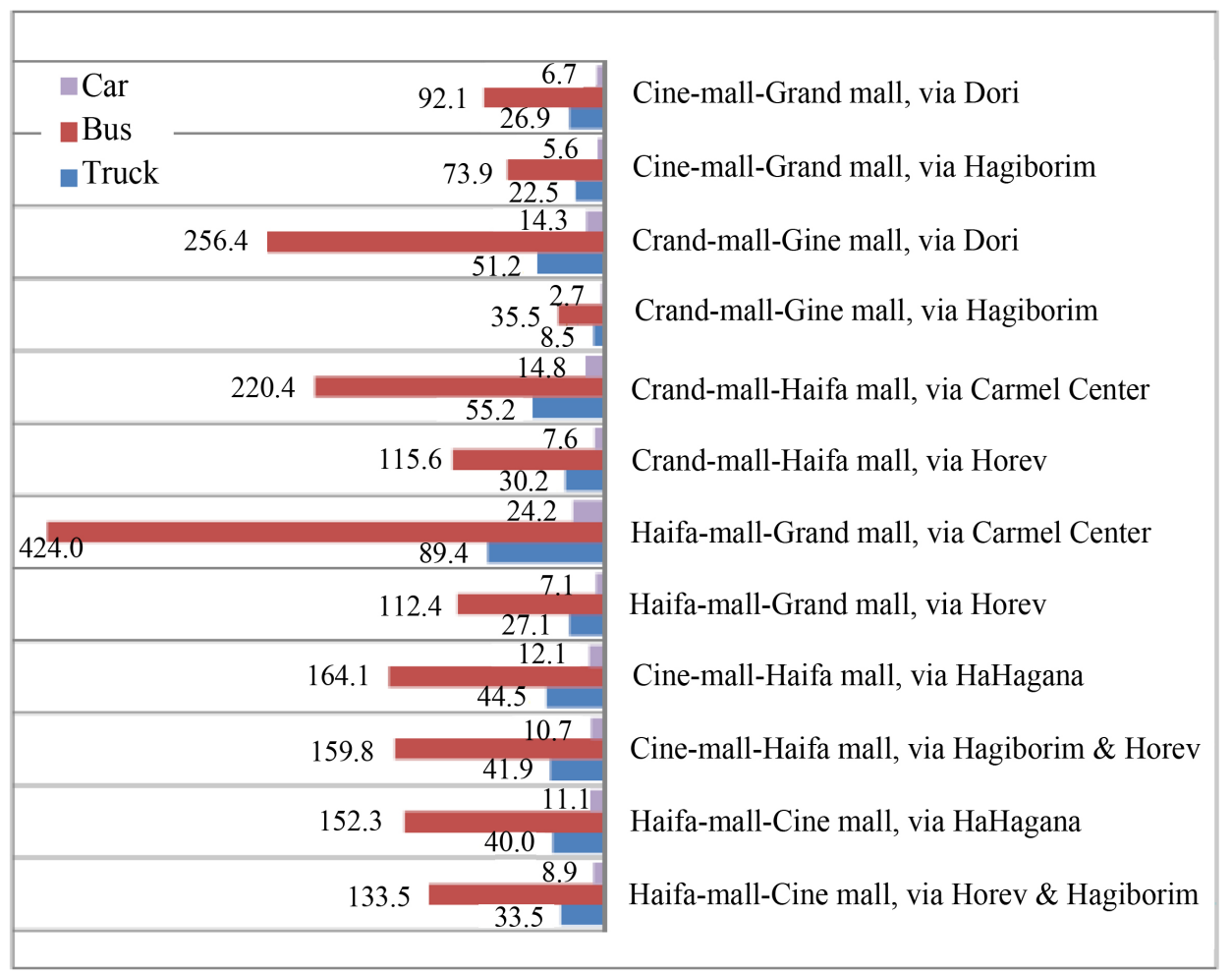

Figure 1. Total economic benefits from driving in the Carmel Tunnels during average hour (NIS per vehicle per section).

\subsection{Benefits from Travelling via the Tunnels during Peak Hours}

During peak hours (about 8 am and $4 \mathrm{pm}$ ), when there is heavy traffic on the alternative routes, the benefit per car increases to NIS 8.46 when driving along one section of the tunnel and to NIS 12.92 when driving along two consecutive sections of the tunnel, as presented in Table 4.

It should be noted that the tunnel toll cost (in August 2015) for a truck was NIS 43.29 and NIS 86.58 for one or two sections, respectively; for a bus NIS 25.98 and NIS 51.96 for one or two section, respectively; and for a car NIS 8.66 and NIS 17.32 for one or two sections respectively. For all alternatives that were analyzed, it is beneficial for a bus to drive through the tunnel (mainly due to time savings of the bus passengers), since the overall benefit for a bus driving via the tunnel compared to alternative routes is 3 times higher than the toll cost of a journey via the tunnel. However, even during peak hours, the cost of driving a truck or a car through the tunnels is higher than the benefits assessed.

However, a more in-depth analysis, shown in Figure 2, (Table 4 presents the average benefits of driving through the tunnels compared to all other alternatives) of each section showed that the direct benefit from driving on the section between Haifa Mall and Grand Mall/Grand Mall-Haifa Mall during peak hour is 35\% higher than the cost of travelling (NIS 11.5/NIS 12.37 total benefit compared to the NIS 8.7 cost of the toll for a private car), meaning that the driver profits from driving via the tunnel. 
Table 4. Benefits from travelling via the tunnels during peak hour (in NIS).

\begin{tabular}{ccccccc}
\hline \multicolumn{7}{c}{ Average for one section at peak hour } \\
& Total & Fuel & Time & Noise & $\begin{array}{c}\text { Air } \\
\text { pollution }\end{array}$ & $\begin{array}{c}\text { Hourly } \\
\text { wage }\end{array}$ \\
\hline Truck & 30.53 & 6.48 & 20.63 & 0.85 & 2.58 & 150 \\
Bus & 124.33 & 9.87 & 110 & 0.55 & 3.90 & $\mathbf{8 0 0}$ \\
Car & 8.46 & 2.41 & 5.50 & 0.26 & 0.29 & $\mathbf{4 0}$ \\
\hline & Average for two sections at peak hour & & Air & Hourly \\
& Total & Fuel & Time & Noise & pollution & Wage \\
\hline Truck & 49.51 & 10.26 & 33.75 & 1.49 & 4.01 & 150 \\
Bus & 201.83 & 15.05 & 180 & 0.96 & 5.82 & $\mathbf{8 0 0}$ \\
Car & 12.92 & 3.07 & 9.00 & 0.45 & 0.40 & $\mathbf{4 0}$ \\
\hline
\end{tabular}

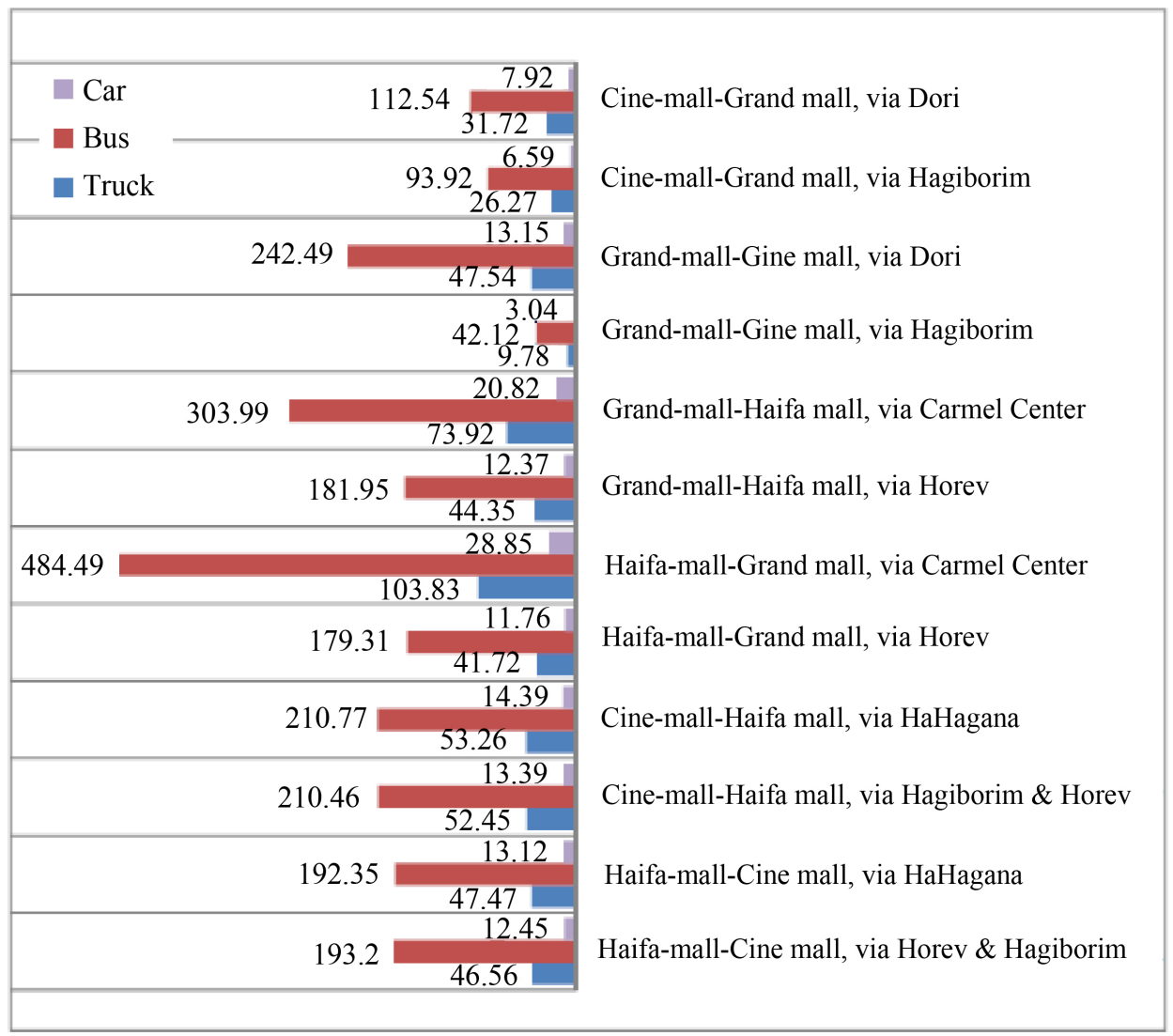

Figure 2. Total economic benefits from driving in the Carmel Tunnels during peak hour (NIS per vehicle per section).

\subsection{The Overall Benefit for the Economy from Using the Carmel Tunnels}

The overall benefit for the Israeli economy from using the Carmel Tunnels is a deriva- 
tive of the degree of use of the tunnels. Based on travel data for 2014 (from January to December) provided by Carmelton, it is possible to quantify the annual benefit of using the tunnels. Findings from this study show that the total annual benefit as a result of using the Carmel Tunnels during 2014 compared to alternative scenarios (The "reasonable" scenario) was NIS $126 \mathrm{M}$.

Table 5 presents the total annual benefit from using the Carmel Tunnels (by all types of vehicles) compared to the most reasonable alternative reference scenario.

Although greater benefits from the tunnels are achieved by heavy vehicles, most vehicles along the tunnels are cars, which is why they account for more than $90 \%$ of the total benefits achieved by using the tunnels.

Time savings can be translated into work days. In total, shortening the time the journey took by using the Carmel Tunnels saved (for drivers only) almost 200,000 work days a year (more than $1.675 \mathrm{M}$ work hours a year).

Fuel savings can also be quantified, with results showing that in total, the tunnels saved 4.5 $\mathrm{M}$ liters of fuel a year (approx. $0.2 \%$ off all transportation fuel consumption in Israel). This saving is equal to 14,000 tons of $\mathrm{CO}_{2}$ per year.

The external benefits of air pollution and noise savings only account for a small part of the benefit ( $5 \%$ each), but environmental and health benefits are important to the public and should not be disregarded, especially in light of the ongoing public debate about the air pollution in Haifa.

\subsection{The Benefit for Haifa Residents as a Result of the Carmel Tunnels}

The degree of exposure to noise by Haifa residents can be calculated based on [23] (i.e., the number of housing units, the number of people per unit, exposure up to 200 meters from the noise source), as can the degree of exposure to air pollution-i.e., the number of people exposed to concentrations that exceed the permitted limit [24].

Overall, about 150,000 residents live in Haifa in neighborhoods adjacent to the Carmel Tunnels or to the alternative routes presented in the reference scenarios. These residents were exposed to less pollution and noise thanks to traffic being redirected to the Carmel Tunnels. The total environmental benefit from improving the quality of the air and reducing noise (not including the time and fuel saving, from which only the driver and passengers benefit) is NIS 9.6 M per year. In other words, each Haifa resident who lives near the relevant roads and routes "earns" NIS 65 a year thanks to the Carmel Tunnels.

Table 5. Total benefits from annual use of the Carmel Tunnels (NIS).

\begin{tabular}{ccc}
\hline & NIS & \% \\
\hline Time savings & $86,901,853$ & $\mathbf{6 9}$ \\
Fuel savings & $29,190,399$ & $\mathbf{2 3}$ \\
Air pollution savings & $4,887,373$ & $\mathbf{4}$ \\
Noise savings & $4,879,997$ & $\mathbf{4}$ \\
Total & $125,859,622$ & $\mathbf{1 0 0}$ \\
\hline
\end{tabular}


It should be mentioned that if the tunnels did not exist as an alternative route, the levels of time loss, fuel waste, noise and pollution presented in this study would, of course, be higher.

\section{Summary and Conclusions}

Using tunnels for transportation allows efficient use of underground land, redirecting traffic congestion from town centers, decreasing landscape damage due to major roads passing through open spaces, and more.

This study analyzed the financial and environmental advantages that are achieved directly and indirectly from using the Carmel Tunnels compared to feasible alternative routes in the City of Haifa.

Direct benefits for the user include financial savings thanks to time and fuel savings. Indirect benefits for the public as a result of others using the tunnels include reduced air pollution, greenhouse gases emissions and noise.

This paper analyzed the actual journeys via the Carmel Tunnels during 2014 compared to alternative routes via the city. All alternatives examined showed a benefit for each parameter (time, fuel, pollution and noise) compared to alternative routes.

With regards to improved air quality in Haifa, an issue that is currently in the headlines, the Carmel Tunnels contribute about NIS $5 \mathrm{M}$ to decreasing emissions each year, $70 \%$ of which are local air pollution savings, with the other $30 \%$ relating to decreased greenhouse gases. The analysis shows that the greatest benefits are generated by buses and trucks compared to cars, with the main reason being the high quantities and type of fuel (diesel) consumed by heavy vehicles, which in turn creates greater air pollution.

As the toll cost paid by drivers for using the tunnels is subject to an agreement between the State of Israel and Carmelton, the government is now (as of January 2016) offering financial incentives for trucks, namely a $40 \%$ reduction of the toll [25]. This incentive will encourage their travelling via the tunnels and to maximize the benefits presented in this paper. It may also be advisable to reduce toll costs for buses and all vehicles during peak hours, thereby encouraging drivers to use the tunnel during these times, as the benefits of using the tunnels during peak time are much higher.

\section{References}

[1] Zaini, F., Hussin, K., Arrifin, A. and Ali, N. (2012) The Future Use of Underground Space in Malaysia: A Literature Review. International Journal of Real Estate Studies, 7, 16-27 https://www.researchgate.net/profile/Farah_Zaini/publication/261667011_The_Future_Use _of_Underground_Space_in_Malaysia_A_Literature_Review/links/0f317534f2a9833973000 000.pdf

[2] Vähäaho, I. (2014) Underground Space Planning in Helsinki. Journal of Rock Mechanics and Geotechnical Engineering, 6, 387-398. http://dx.doi.org/10.1016/j.jrmge.2014.05.005

[3] Carmody, J. and Sterling, R. (1993) Underground Space Design: A Guide to Subsurface Utilization and Design for People in Underground Spaces. Van Nostrand Reinhold, New York.

[4] Shechter, M. and Ayalon, O., Eds. (2012) Israeli Climate Change Information Center (ICCIC). Report No. 1-Status Report and Knowledge Gaps. 266 p. (Hebrew). 
http://www.neaman.org.il/Neaman2011/Templates/ShowPage.asp?DBID=1\&LNGID=2\&T $\underline{\mathrm{MID}}=581 \& \mathrm{FID}=646 \& \mathrm{IID}=9613$

[5] The World Bank (2014) Motor Vehicles (per 1,000 People). http://www.who.int/gho/road_safety/registered_vehicles/number/en/

[6] Carta, F. and De Philippis, M. (2015) You've Come a Long Way, Baby. Effects of Commuting Times on Couples' Labour Supply. Working Papers. Bank of Italy, Rome.

[7] Capon, A.G. (2007) The Way We Live in Our Cities. The Medical Journal of Australia, 187, 658-661.

[8] Krzyżanowski, M., Kuna-Dibbert, B. and Schneider, J. (2005) Health Effects of TransportRelated Air Pollution. WHO Regional Office Europe, Copenhagen.

[9] Becker, N., Rosenthal, G. and Gabay, D. (2012) Externalities of Air Pollutants from Transportation and Industry (Hebrew). http://www.sviva.gov.il/subjectsenv/svivaair/documents/airexternalcost/airnirb_1.pdf

[10] Santo, G., Behrendt, H., Maconi, L., Shirvani, T. and Teytelboym, A. (2010) Part I: Externalities and Economic Policies in Road Transport. Research in Transportation Economics, 28, 2-45. http://dx.doi.org/10.1016/j.retrec.2009.11.002

[11] Mustapha, B.A., Blangiardo, M., Briggs, D.J. and Hnasell, A.L. (2011) Traffic Air Pollution and Other Risk Factors for Respiratory Illness in Schoolchildren in the Niger-Delta Region of Nigeria. Environmental Health Perspectives, 119, 1478-1482. http://dx.doi.org/10.1289/ehp.1003099

[12] Raaschou-Nielsen, O., Jovanovic Andersen, Z., Hvidberg, M., Solvang Jensen, S., Ketzel, M., Sørensen, M., et al. (2011) Lung Cancer Incidence and Long-Term Exposure to Air Pollution from Traffic. Environmental Health Perspectives, 119, 860. http://dx.doi.org/10.1289/ehp.1002353

[13] Simmons, W.A. and Seakins, P.W. (2012) Estimations of Primary Nitrogen Dioxide Exhaust Emissions from Chemiluminescence NOx Measurements in a UK Road Tunnel. Science of the Total Environment, 438, 248-259. http://dx.doi.org/10.1016/j.scitotenv.2012.08.050

[14] Lai, C.H. and Peng, T.P. (2012) Volatile Hydrocarbon Emissions from Vehicles and Vertical Ventilations in the Hsuehshan Traffic Tunnel, Taiwan. Environmental Monitoring and Assessment, 184, 4015-4028. http://dx.doi.org/10.1007/s10661-011-2240-2

[15] Cowie, C.T., Rose, N., Gillett, R., Walter, S. and Marks, G.B. (2012) Redistribution of Traffic Related Air Pollution Associated with a New Road Tunnel. Environmental Science and Technology, 46, 2918-2927. http://dx.doi.org/10.1021/es202686r

[16] Hashko, Y. (2014) The Effects of the Carmel Tunnels on Air Quality in the City of Haifa. Master Thesis, University of Haifa, Haifa, 90 pp.

[17] Ongel, A., Harvey, J.T., Kohler, E., Lu, Q. and Steven, B.D. (2008) Investigation of Noise, Durability, Permeability, and Friction Performance Trends for Asphaltic Pavement Surface Types: First-and Second-Year Results (No. UCPRC-RR-2007-03).

[18] WAZE Website (2015). https://www.waze.com/livemap

[19] Google Earth Website (2015). https://www.google.com/earth/

[20] Israel Ministry of Environmental Protection (2014) Guidelines to conduct an environmental assessment of transportation.

http://www.sviva.gov.il/subjectsEnv/SvivaAir/CarPollution/Documents/Seker_AirPollution Transpotration22014.pdf

[21] Israel Ministry of Environmental Protection (2014) Calculating air emissions from trans- 
portation.

http://www.sviva.gov.il/subjectsEnv/SvivaAir/CarPollution/Types/Pages/default.aspx

[22] Israel Ministry of Environmental Protection (2015)

http://www.sviva.gov.il/subjectsenv/svivaair/documents/airexternalcost/airpollutionvalue11 .2.2015.pdf

[23] EATP (2006).

http://media.mot.gov.il/PDF/HofesMeyda/NOALP/Appendix6EnvironmentalImpact.pdf

[24] Paz, S., Linn, S., Portnov, B.A., Lazimi, A., Futerman, B. and Barchana, M. (2009) Non-Hodgkin Lymphoma (NHL) Linkage with Residence Near Heavy Roads-A Case Study from Haifa Bay, Israel. Health \& Place, 15, 636-641.

http://dx.doi.org/10.1016/j.healthplace.2008.10.004

[25] Israel Ministry of Environmental Protection (2016) Haifa Bay Action Plan: Quarterly Report.

http://www.sviva.gov.il/YourEnv/CountyHaifa/HaifaBay/Pages/transportation-HaifaBay.as $\mathrm{px}$

\section{Submit or recommend next manuscript to SCIRP and we will provide best service} for you:

Accepting pre-submission inquiries through Email, Facebook, LinkedIn, Twitter, etc. A wide selection of journals (inclusive of 9 subjects, more than 200 journals)

Providing 24-hour high-quality service

User-friendly online submission system

Fair and swift peer-review system

Efficient typesetting and proofreading procedure

Display of the result of downloads and visits, as well as the number of cited articles Maximum dissemination of your research work

Submit your manuscript at: http://papersubmission.scirp.org/ 